\title{
Self-Regulatory Learning Behaviours in Open and Distance Learning: Priming Appropriate Online Mediation Contexts for Multicultural Students
}

\author{
Jabulani Nyoni \\ Department of Educational Leadership and Management \\ University of South Africa, South Africa \\ nyonij@unisa.ac.za
}

\section{Doi:10.5901/mjss.2014.v5n15p441}

\begin{abstract}
As more open and distance learning $(O D L)$ institutions avail their curricula to a diverse range of multicultural students through a variety of blended methodologies, lecturers/facilitators are expected to craft appropriate instructional contexts and activities than rely on orthodox knowledge-based curricula. In order to succeed to this endeavour, lecturers must, at all times, be reflective and analytical about their own beliefs and practices and acquire a deeper understanding of cognitive and motivational principles of multicultural self-regulated learning and agency. The e-narrative analysis of data collected through a qualitative highly flexible online asynchronous online bulletin board (OBB) and the use of a focus group format in which pre-recruited respondents logged on at any time convenient to them indicated that ODL multicultural students in the majority of cases feel that learning experience schemas primed by lecturers that are destined to promote agencies and make online self-regulatory learning behaviours effective are somewhat inadequate and inappropriate in developing countries like South Africa. I proffer that ODL mediation contexts and activities primed by lecturers for andragogical multicultural online self-regulatory learning behaviours must include student-centred or critical inclusion, the inclusion of the voices and perspectives of the students themselves in the educational experiences in order to undergird social agency.
\end{abstract}

Keywords: Online self-regulatory learning behaviours; social-agency; open and distance learning (ODL); multiculturalism; connectivism

\section{Introductory Remarks}

Open and distance learning (ODL) and online learning environments (OLEs) are indeed unique conceptions that require contextual analysis in order to allay myths and misconceptions about them. Moore (1991; 1993) discusses the unique context of ODL as a mediation theory and online learning environment as one of the delivery modus operandi from the perspective of facilitator-learner/student relationships. According to Moore $(1991 ; 1993)$, the facilitator and learner in ODL online mediation traffic are always separated by space and sometimes both time and space. This separation by space creates a psychological or transactional distance between the learner and the facilitator/instructor. The degree to which this transactional distance affects the teacher-learner relationship appears to be the function of three clusters of variables referred to as: (a) dialogue, (b) structure, and (c) learner autonomy (Moore, 1993). Moore's learner autonomy can be likened to the ability of learner's self-regulation from the social cognitive perspective.

Moore (1993, p.31) defines learner autonomy as "the extent to which in the teaching/ learning relationship it is the learner rather than the facilitator/instructor who determines the goals, the learning experiences, and the evaluation of decisions. ..." From the perspective of the theory of transactional distance, learners who are more autonomous or selfregulated appear to be more comfortable in online or distance programmes than learners who are less autonomous or self-regulated, at least according to Moore (1993, p.32). For online courses in particular, Howland and Moore (2002) have indicated that self-regulatory learning behaviours are important for courses delivered through the use of the internet, and as being associated with more positive academic outcomes including student retention and program satisfaction. In examining the open-ended responses of 48 online students, Howland and Moore (2002) additionally found that students who engaged in more online self-regulatory learning behaviours generally had more positive perceptions of online courses. The magnitude and form of the relationship among student perceptions of online course communication and collaboration, self-regulatory learning behaviours, and academic achievement in online courses, however, has yet to be quantitatively and qualitatively examined.

In a qualitative study of online course curriculum and instruction, Fisher and Baird (2005) found that fostering a sense of community positively influenced student retention over the course of a period of two years. Noting that this 
sense of community and support felt by students was associated with increased online self-regulatory learning behaviours, Fisher and Baird (2005) also found that students engaging in communication online tended to want to meet peer expectations and to be valued in the eyes of their peers, and thus were more likely to choose to engage in online self-regulatory learning behaviours to meet those expectations. Fisher and Baird (2005) concluded two means of encouraging student self-regulation was (a) peer evaluations and (b) small group projects which served to create an online learning environment wherein students feel accountable to meet the expectations of others. In this way, Fisher and Baird (2005) highlight means of improving student learning by priming a social interaction schema within the learner, essentially fuelling their sense of social agency. Due to the student-desired end of social acceptance and desirability by others, collaborative group activities serve as means of improving student online learning.

Culture is a uniquely human trait. As a vehicle of human expression, it cannot exist apart from human society, and likewise, no human society can exist without it. It is an expression of identity recognizable in every form of communication, be it through language, music, literature, art, dance, and even cuisine. Many cultural traits in Africa and also around the world have been exchanged and adopted among the peoples to the extent that they can no longer be indicative of a single culture (Nyoni, 2012). The PhD study by Nyoni (2012) on multicultural team approach on curriculum and learning development found that the metamorphosis of cultural traits has spilled over into educational terrains thus have a direct bearing on pedagogical content knowledges (PCKs) of lecturers/facilitators. In Nyoni's (2012) follow-up study the following question was used to explore how multicultural students experience learning contexts and activities schemas primed by ODL lecturers given the multicultural diversity nature of students in ODL institutions:

What are the views of self-regulatory ODL postgraduate multicultural students on learning experiences schemas primed by lecturers that are designed to promote agencies that make online learning behaviours effective?

\section{Theoretical Framework Undergirding the Study}

Recently, there has been a move towards constructivism. Constructivist theorists claim that learners interpret the information and the world according to their personal reality, that they learn by observation, processing, and interpretation, and then personalize the information into personal knowledge (Cooper, 1993; Wilson, 1997). Learners learn best when they can contextualize what they learn for immediate application and personal meaning. It becomes more crucial for lecturers/facilitators to prime appropriate learning experiences for self-regulatory multicultural students in ODL.

When new ODL lecturers have acquired an understanding of the social and situated nature of learning, an appreciation of the importance of authentic contexts, the habit of reflecting upon their own experiences, and the willingness to question their own assumptions and beliefs, then they will be more prepared to create the kinds of learning climates that will enable students to learn the lessons that really matter who advocated that future teachers use a psychological perspective on learning to create a coherent framework of ideas about student learning (Anderson, Blumenfeld, Pintrich, Clark, Marx, \& Peterson, 1995).

\section{The Need for Multiculturalism Recognition in Online ODL Mediation}

But contrary to the growing flatness that Friedman (2007) reports, cultural diversity remains apparent among learners, perhaps owing to deeply rooted cultural values and modes of thinking that are difficult to separate from learning processes (Nisbett, 2003). A growing appreciation of cultural diversity is demonstrated by more than its acknowledgement and tolerance, but also by a desire to preserve that diversity as a valuable asset for addressing the many challenges faced by the global community now and in the future. Additionally, one can recognize a strong desire to preserve diversity in response to the threat of loss of cultural identity in the face of globalization and because of the benefits of community cohesiveness through unique cultural expression (Mason, 2007).

Numerous factors are converging that make ODL mediation in cross-cultural and multicultural contexts more commonplace. Expanding world trade and globalization of industry, finance, and many professions are creating a world in which multicultural interactions occur more frequently than at any time in the past (Friedman, 2007).

\section{Multicultural Agency in ODL Online E-Education}

Agency is the capability of individuals to consciously choose, influence and structure their actions (Emirbayer \& Mische, 1998; Gecas, 2003) and it is an active exercise of ability and will. The ways in which individuals express agency are associated with their motivational orientation, intentionality, and choice (volition), and relates to their ability to engage 
these characteristics in social contexts to achieve their goals. As agents, individuals formulate intentions, execute decisions, and produce motivation in an effort to communicate. Understanding how agency develops and emerges within social networks is a key factor in identifying why online social networks develop and how they influence individual processes such as cognition, motivation, behaviour, and ultimately learning.

Agency is an ability developed through social means and human experience (Mead, 1932; 1934). As an ability to act independently despite the immediate situation, agency engages habit, imagination, and judgment (Emirbayer \& Mische, 1998, p.970). Agency also involves the knowledge, experience, and the ability to achieve one's goals (Little, Hawley, Henrich, \& Marsland, 2002).

The ways in which individuals express and develop agency are associated with their motivational orientation, intentionality, and choice, and speaks to their ability to engage these characteristics in social contexts to achieve their particular goals. Internal personal factors, behavioural patterns, and environmental influences require agency ability to facilitate social processes. Individuals come to believe that they can communicate relatively successfully, and ultimately develop a higher self-efficacy for socialization and feel that they have control over their actions within this particular context. As a result, individuals who have high self-efficacy also have a tendency to believe that they control their actions and the outcomes that result.

In ODL e-education, conceptualizing social software as a cultural tool, using social networks to represents multiple ways of knowing, knowledge-building, promoting communities of practice, and enabling self-regulated learning, enables a clear application of social software as an educational tool.

\section{Multicultural Online Self-Regulatory Learning Behaviour}

Self-regulated learning has been referred to as the desired outcome of the process of "students' self-generated thoughts and behaviours that are systematically oriented toward the attainment of their learning goals" (Zimmerman \& Schunk, 2001, 125). Self-regulation as such can be viewed as the requisite discipline of the individual in their learning process, whether this process takes place in an online or face-to-face environment. Examples of self-regulatory behaviours in learning include, but are not limited to, goal setting and environment structuring. Some of these self-regulatory behaviours, like goal setting, appear to be more explicit, while others, like environment structuring (e.g., turning off a television while you work), appear to be more implicit. Whether implicit or explicit, these self-regulatory behaviours do have an effect on the achievement and performance of learners.

As applied to learners in online environments, the development of self-regulatory skills would appear to be first derived from the online learning environment factors, where learners would receive feedback from their behaviours in these online environments (e.g., lack of checking in online leading to missed assignment deadlines, etc.). While selfregulatory behaviours in online learning environments would appear to develop similarly as in other domains, selfregulatory behaviours have been indicated as being "highly context dependent" (Zimmerman \& Schunk, 2001, 125) requiring the examination of self-regulatory behaviours within the context of the online learning environment.

Online and distance learning environments are, indeed, unique contexts requiring examination. Moore (1991; 1993) discusses the unique context of the distance or online learning environment from the perspective of teacher-learner relationships. According to Moore (1991; 1993), the teacher and learner in online or distance learning are always separated by space and sometimes both time and space. This separation by space creates a psychological or transactional distance between the learner and instructor. The degree to which this transactional distance affects the teacher-learner relationship appears to be the function of three clusters of variables referred to as: (a) dialogue, (b) structure, and (c) learner autonomy (Moore, 1993). Moore's learner autonomy can be likened to the ability of learner's self-regulation from the social cognitive perspective. Moore (1993, p.31) defines learner autonomy as "the extent to which in the teaching/ learning relationship it is the learner rather than the teacher who determines the goals, the learning experiences, and the evaluation of decisions..."

\section{Methodological Underpinnings}

An "asynchronous" online bulletin board (OBB) is a highly flexible online tool that was used to collect data. Virtual Focus Group (VFG) format in which purposively pre-recruited respondents logged on at any time convenient to them, answered posted topical themes and engaged in online discussion with a moderator (researcher) and other group members was used. An OBB virtual focus group took place over a 3-5 day period - with respondents participating 2-3 times each day. Because of the longer timeframe and the come-and-go nature of the discussion, most OBB discussions had 10-20 participants (eighty per cent of which were females (80\%)), rather than the 8-10 participants common with in-person or 
real-time online groups. The table provides a synthesized explanation on how data was populated and interpreted.

Items making up reasons for OBB use were collected by posting topical themes online on several OBBs asking users to enumerate their views on the efficacy of the learning experiences chimed by lecturers on the module, Legal Issues at postgraduate level. Responses were later refined and reformed into several themes. These themes were later posted on arbitrarily chosen OBBs accompanying 5-point of interval level scales starting with "Strongly agree" and ending with "Strongly disagree". After obtaining about 150 responses, the results were subjected to factor analysis to classify matching themes into specific factors. Finally, an alpha reliability test was run to check the scores. Themes were then finalised and posted along with other themes in English (see the complete listing of items and their alpha reliability scores in table 1).

Table 1: Rotated factor analysis

\begin{tabular}{|c|c|c|c|c|c|}
\hline \multicolumn{6}{|c|}{$\begin{array}{l}\text { Rotated factor analysis of views on the use of experienced schemas primed by lecturers to promote agencies that } \\
\text { make online self-regulatory learning behaviours effective: }(\mathrm{N}=342) \ll<<\text { Dear Author: Please confirm if my corrections } \\
\text { above are correct. Thank you, Robert } \gg \gg\end{array}$} \\
\hline \multirow{3}{*}{ "My views on } & & & & & \\
\hline & \multicolumn{2}{|c|}{ Descriptive mean } & \multicolumn{3}{|c|}{ Themes } \\
\hline & Mean & SD & 1 & 2 & 3 \\
\hline \multicolumn{6}{|c|}{$\begin{array}{l}\text { Catering for diverse multicultural views in curricula }(A v \text { mean }=1.7 ; A v S D=1.1 ; \text { rank of perceived gratification = } \\
\text { 1.02) }\end{array}$} \\
\hline $\begin{array}{l}\text { Lecturer's responses to my reaction mediation scenarios relating to my } \\
\text { situation }\end{array}$ & 1.2 & 0.71 & 0.485 & 0.096 & 0.039 \\
\hline Lecturer's responses to my own situational experiences & 2.1 & 0.69 & 0.555 & 0.081 & 0.036 \\
\hline Lecturer's sensitivity to my considered views and experiences & 1.8 & 0.79 & 0.453 & 0.071 & 0.020 \\
\hline \multicolumn{6}{|c|}{ Priming of appropriate mediation experiences ( $A v$ mean $=1.3 ; A v S D=1.11 ;$ rank of perceived gratification $=0.76$ ) } \\
\hline Diversity of scenarios that relate to diverse group of people. & 1.1 & 0.72 & -0.029 & 0.090 & 0.006 \\
\hline Appropriateness of activities to diverse group of students & 0.9 & 0.79 & -0.054 & 0.058 & 0.043 \\
\hline $\begin{array}{l}\text { Lecturer's inclusion of international legal instruments so that we can all be } \\
\text { able to respond using cases in our own countries }\end{array}$ & 1.8 & 0.71 & 0.037 & -0.066 & 0.163 \\
\hline \multicolumn{6}{|c|}{$\begin{array}{l}\text { Promoting and sustaining understanding of the multicultural context of society (Av mean }=1.5 ; A v S D=0.64 \text { (rank } \\
\text { of perceived gratification }=0.92 \text { ) }\end{array}$} \\
\hline Lecturer's ability to manage a multicultural group of students & 2.1 & 0.74 & -0.051 & -0.009 & 0.086 \\
\hline Lecturer's tolerance of plurality of cultural views & 1.5 & 0.00 & 0.039 & 0.080 & 0.130 \\
\hline Allowing students engage each other on issues that affect them & 1.0 & 0.5 & 0.019 & -0.070 & 0.003 \\
\hline \multicolumn{6}{|c|}{ Assessing multicultural competency skills (Av mean $=1.2 ; \mathrm{Av} S \mathrm{SD}=0.86$; rank of perceived gratification $=0.72$ ) } \\
\hline Lecturer's use of a range of assessment tools & 1.3 & 0.72 & -0.059 & 0.031 & 0.037 \\
\hline Lecturer's ability to include students in assessment & 1.1 & 0.69 & -0.051 & 0.004 & 0.017 \\
\hline Use of other assessment methods other than summative & 1.2 & 0.3 & -0.043 & -0.063 & 0.016 \\
\hline Eigenvalue & 12.80 & 1.86 & 1.33 & 1.14 & 1.00 \\
\hline Proportion (\%) & 47.41 & 6.88 & 4.93 & 4.23 & 3.71 \\
\hline Cumulative (\%) & 47.41 & 54.3 & 59.2 & 63.45 & 67.15 \\
\hline
\end{tabular}

With the ability to embed video and other multimedia with the click of a button, this media allowed the researcher to tap into the rich world of user-generated content and narrative activities by downloading 181136 trends most of which were repetitive but were whittled down to 342 consolidated figure ( $N=342$ ).

\section{Data Analysis and Results}

The large volumes of data generated provided challenges for fast turnaround of results - data was carefully structured to facilitate analysis. OBB raw data was exported into a searchable database which enhanced the researcher's ability to manage multi-site data streams and efficiently query and code data to generate insight. For the preliminary factor analysis procedure, a loading level of 0.50 was selected as the criterion to retain an item within a factor. Two items that fell below that level were dropped therefore. An Eigenvalue of one or more was also specified for considering a 
combination of items as a factor. Finally, Principal Component analysis was used for extraction and the Varimax method for data rotation. The statistical analysis resulted in the identification of four factors (reasons), each having an Eigenvalue of at least one: manipulation, 4.53; belonging, 1.68; reciprocal exchange/expression, 1.42; and autonomy, 1.26. Together these four factors explained $68 \%$ of the variance (table 1). However statistical information provided pointers or indicators to where I could probe in order to identify the most appropriate themes for further probing. Reporting was provided at various levels.

- Initial insights were provided via downloadable transcripts at the end of each day.

- Full transcripts, exported were consolidated into the searchable database format that was created.

- Team-based analyses were fed into PowerPoint reporting which was shared with ODL multicultural students as well as lecturers at an early stage.

- Students' sentiments, views and experiences on mediation processes primed by lecturers were captured and subsequently analysed using thematic approach.

- Lecturers' responses on the same question were also captured and analysed.

\section{Discussion of Findings}

Olstad, Foster, and Wyman (1983) indicate that lecturers and/or facilitators lacking multicultural education are inadequately prepared for the reality of a pluralistic society and tend to have low expectations for minority students. ODL lecturers must ask themselves to what degree their mediation programmes (a) facilitate increased cultural selfawareness, (b) cultivate appreciation of diversity, (c) increase cultural competency, and (d) prepare students to engage their peers on critical multicultural issues. To the extent that mediation materials achieve these ends, to what extent do they acquire knowledge and skills will make them multiculturally competent mediators of learning in ODL. A thematic analysis involved an iterative process that yielded four themes (table 1).

\section{Catering for Diverse Multicultural Views in Curricula}

Multiculturalism, as a systematic and comprehensive response to cultural and ethnic diversity, with educational, linguistic, economic and social components and specific institutional mechanisms, has been adopted by a few countries, notably; Australia, Canada and Sweden (UNESCO, 2003).

Understandably, multiculturalism as a search for democratic public policy responses to cultural and ethnic diversity in certain countries is of prime interest to UNESCO (2003), in so far as it embodies the ideal of reconciling respect for diversity with concerns for societal cohesion and the promotion of universally shared values and norms.

Inclusion refers to the extent to which different voices and perspectives are heard in my classroom. There are two levels of inclusion. When most teachers talk about inclusion, they are referring to representational inclusion, or the inclusion of sources or information that closely match or represent the diversity within a particular classroom. One common thread of a discussion student kept on stating in blog read for example;

I happen to have a black South African student in my class; I expect to find material authored by black South Africans included in the source packs so that I can share such materials with other peers.

The second level of inclusion is student-centred or critical inclusion, the inclusion of the voices and perspectives of the students themselves in the educational experience. Students are the most under-utilized educational resource in most teaching and learning experiences. One strong comment read:

Honestly allow the students' voices to be included in the resource materials and allow us engage each other on them issues that affect our lives. Some of these examples are boring and irrelevant to my circumstances and experiences.

A multicultural curriculum encourages them to provide context and perspectives on all subjects covered in school.

\section{Priming of Appropriate Mediation Experiences}

Largely, the success of a multicultural classroom depends on an instructor's level of multicultural awareness. In counselling the culturally different, Sue and Sue (2010) describe a tripartite framework of multicultural awareness. This theory indicates that an individual must (a) be aware of themselves and others, (b) have knowledge about different 
cultures, and (c) utilize appropriate skills to interact with multicultural populations. In a multicultural online blog, an instructor's attitude (either flagrant or subversive) can set the tone for the blog. In this way, it becomes important for instructors to be aware of themselves in a multicultural context and incorporate inclusiveness into their classroom instruction and management. Having an attitude of inclusion goes a long way in setting a multicultural tone for the blog. Many instructors find that an open and inclusive attitude towards diversity originates from their own early experiences. Let me consider one of the activities primed by a lecturer who teaches Education Law in South Africa:

Affirmative Action implementation in South Africa. Prepare a portfolio on how a Black or White teacher can be chosen over the other. The School Governing Body selection committee has to make a decision between a Black inexperienced lady teacher and an experienced White lady teacher. Support your decision by referring to the prescripts of the law.

The activity might be relevant to certain sections of South African students and can be justifiably declared unconstitutional by some. The same activity can be inappropriate to other students outside of South Africa.

One student reports that she was a youth in South Africa educated in both pre- and post-apartheid school systems. Her family's commitment to social responsibility and her own involvement in social change movements, she reports, inspired her and now influences her attitudes toward inclusiveness in the blog and finds it retrogressive when the system still classifies people according to colour. Not only must instructors be aware of themselves and their attitudes, they must also be aware of the diversity of students.

Instructors often need to orient diverse students to the learning process and allow them to share their unique social and cultural histories in the classroom (Allen, Taleni, \& Robertson, 2009). This can be a sensitive and complicated manoeuvre. When done well, it allows students to openly express themselves as unique individuals and enrich the classroom experience.

\title{
11. Promoting and Sustaining Understanding of the Multicultural Context of Society
}

Fostering and cultivating such dialectical insight in multicultural lecturers goes well beyond simple skills training or memorizing the traits and customs of various cultures. For example, a Zambian who dialogues with a deceased ancestor for advice and solace may be perceived as delusional or psychotic by traditional western mental health standards. As one student wrote:

\begin{abstract}
In times of difficult and need, we converge at ancestral home and homage to our ancestors for having looked after us as well as having provide for us and sustained our (sic) over the year. We sacrifice an animal of some sort particularly a beast for cleansing purposes as well a (sic) asking for their continued blessings.
\end{abstract}

Finally, field experiences and teacher supervisors must incorporate a multicultural focus. Lecturers should observe diversity in the mediation platforms and how online lecturers apply multicultural teaching practices. Just as foundation and methodology instructors provide knowledge and techniques for teaching in culturally diverse platforms, so should lecturers and cooperating tutors nurture and inspire students to apply culturally appropriate strategies. Carefully designed student teaching in a multicultural setting allows students to probe their own multicultural competency, to put into practice the culturally sensitive strategies that they have learned, and to reflect on the effectiveness of their own teaching on student learning.

\section{Assessing of Multicultural Competency Skills}

Ultimately, lecturers need to assess the multicultural competency of their contexts and activities, that is, how effectively self-regulatory students interact with their peers, adopt behaviour that respects and responds to multicultural diversity, and integrate multicultural diversity into their mediation contexts. This task is not easy because, just as good mediation incorporates many factors, multicultural competency encompasses numerous components. Furthermore, educational and personal philosophies determine which behaviours lecturers believe demonstrate multicultural competency. Hence the selection of universally accepted identifiers of multicultural competency is almost impossible and of limited value. To illustrate what I mean by a lecturer being multiculturally conscience of the need to craft contexts and activities that are able to appeal, attract, motivate and sustain self-regulatory ODL multicultural students, responses gleaned from the thread read;

Some of the activities posted online are at times boring and do not speak to me and I find it very hard to engage my peers on some of the exemplar used (sic). Not stimulating (sic) I mean not stimulating at all. 


\section{Recommendations}

Gray and Wood (1991, p.4) define collaboration as "a process through which parties who see different aspects of a problem can constructively explore their differences and search for solutions that go beyond their own limited vision of what is possible". Collaboration can therefore further the processes of shared decision-making, creation of new information and trust among andragogical self-regulatory online students. In an effort to build collaborative alliances among students and between students and the facilitator it is imperative to establish a genuine sense of community based on trust (Hooks, 2010, p.109). Hooks (1994, p.39) further asserts that, "it is the absence of a feeling of safety that often promotes prolonged silence or a lack of student engagement". To foster an element of trust and a sense of belonging and engagement with others Freire (1997) emphasizes dialogue. Freire (1997) was concerned with praxis - an action that is informed (and linked to certain values). Dialogue wasn't just about deepening understanding - but was part of making a difference in the world. Dialogue in itself is a cooperative activity involving respect. The process is important and can be seen as enhancing the community and building social capital and leads them to act in ways that make justice and human being flourish. By constructing a safe community grounded in trust, students would have to have the ability to become more involved in the collaborative efforts and the co-construction of knowledge as related to whatever they are involved with as students. Knowles (1980, p.44) explains that adults become ready to learn when, "they experience a need to learn it in order to cope more satisfyingly with real-life tasks or problems". Andragogical learners want to know that what they are learning will have real-life applications (Fidishun, 2010).

Fidishun (2010) further elaborates that for adult learners internal priorities are most important; especially as they are related to increased job satisfaction, self-esteem and quality of life. Parallel to this idea, Palloff and Pratt $(2007,109)$ advocates for "creating a learning community that is intellectually exciting and challenging; and encourage learners to perform to the best of their abilities in all aspects". Keeping these efforts in mind, facilitators can solicit ongoing feedback about the importance and relevance of on-going activities based in multiculturalism; have students attest to times when they have felt oppressed, as the "other," or marginalized; incorporate activities that ask students to step out of the bounds of their own zones of privilege and put themselves situations in which they are the minority; and have students coconstruct projects based on real-world applications of multicultural campaigns.

\section{Conclusion}

Indeed, the question of how best to design, implement and evaluate innovative and creative international and national online curricula remains of great interest, especially in South Africa context where connectivity remains a challenge and multicultural discourse remain in the public domain (Curro \& McTaggart, 2004; Beattie, 2004; Reid \& Loxton, 2004; Ninnes \& Hellstén, 2005). Of special importance in this context are the pedagogical practices that can facilitate the acquisition of "international" "national" and "multicultural" knowledge and skills, both in self-regulating students and their lecturers. These pedagogical practices can be achieved by the maximum use of blended student centred mediation online tools that promote self-regulating learning in ODL.

The study found out that self-regulatory ODL multicultural students in the majority of cases feel that learning contexts schemas primed by lecturers that are destined to promote agencies and make online self-regulatory learning behaviours effective are somewhat inadequate and inappropriate as it will appear that lecturers in post-apartheid South Africa still rely on orthodox methodologies. The reliance on orthodoxies fails to take into cognisance students' ereadiness, multicultural dynamics and connectivity challenges in some places in South Africa. Self-regulatory behaviours in learning on the part of students were difficult to cultivate and sustain as more often than not, either students were not e-ready to learn with tools such as computers particularly in rural areas or connectivity was not available the time they wanted to engage lecturer and their peers.

\section{References}

Allen, P., Taleni, L., \& Robertson, J. (2009). "In order to teach you, I must know you." The Pasifika initiative: A professional development project for teaching. New Zealand Journal of Education Studies, 44(2), 47-62.

Anderson, L.M., Blumenfeld, P., Pintrich, P. R., Clark, C. M., Marx, R. W., \& Peterson, P. (1995). Educational psychology for teachers: Reforming our course, rethinking our roles. Educational Psychologist, 30(7), 143-157.

Beattie, K. (2004). Internationalising Teaching. Centre for the Study of Higher Education, Melbourne University, (18 December 2005); http://www.cshe.unimelb.edu.au/downloads/international_teach_rev2.pdf.

Cooper, P.A. (1993). Paradigm shifts in designing instruction: From behaviourism to cognitivism to constructivism. Educational Technology, 33(5), 12-19. 
Curro, G., \& McTaggart R. (2004). Supporting the Pedagogy of Internationalisation, presented at the 17th IDP Australian International Education Conference (21-24 October), Melbourne,

Australia. (17 December 2005); http://www.jcu.edu.au/office/tld/teachingsupport/documents/Supporting pedagogy internat.pdf.

Downes, S. (2006). An introduction to connective knowledge. Retrieved March 26, 2007, from http://www.downes.ca/post/33034

Emirbayer, M., \& Mische, A. (1998). What is agency? American Journal of Sociology, 103(4), 962-1023.

Freire, P. (1997). Pedagogy of the oppressed. New York, NY: Continuum Publishing.

Gay, G. (2000). Culturally Responsive Teaching: Theory, Research, \& Practice. New York: Teachers College Press.

Gecas, V. (2003). Self-agency and the life course. In J. T. Mortimer \& M. J. Shanahan (Eds.), Handbook of the Life Course. New York, NY: Kluwer Academic Publishing/Plenum Publishers.

Gray, B., \& Wood, D. (1991). Collaborative alliances: Moving from theory to practice. Journal of Applied Behavioral Science, $27(1), 3-22$.

Hollins, E.R. (1996). Culture in School Learning: Revealing the Deep Meaning. Mahwah, NJ: Erlbaum.

Hooks, B. (1994). Teaching to transgress: Education as the practice of freedom. New York: Routledge.

Hooks, B. (2010). Teaching critical thinking: Practical wisdom. New York, NY: Routledge.

Knowles, M. (1980). The modern practice of adult education: From andragogy to pedagogy. Englewood Cliffs, NJ: Cambridge Adult Education.

Ladson-Billings, G. (1995a). But that's just good teaching! The case for culturally relevant pedagogy. Theory Into Practice, 34(3), 159165.

Little, T.D., Hawley, P.H., Henrich, C.C., \& Marsland, K.W. (2002). Three views of the agentic self: A developmental synthesis. In E. Deci \& R. Ryan (Eds.), Handbook of self-determination research (pp. 390-404). Rochester, NY: University of Rochester Press.

Mead, G.H. (1932). The philosophy of the present. Chicago, IL: University of Chicago Press.

Mead, G.H. (1934). Mind, self and society from the standpoint of a social behaviorist. Chicago, Il: Chicago University Press.

Moore, M. G. (1991). Distance education theory. The American Journal of Distance Education, 5(3), 1-6.

Moore, M. G. (1993). Theory of transactional distance. In D. Keegan (Ed.), Theoretical principles of distance education (pp. 22-38). New York: Routledge.

Ninnes, P., \& Hellstén, M., eds. (2005). Internationalizing Higher Education: Critical Explorations of Pedagogy and Policy. CERC Studies in Comparative Education 16., Springer: Dordrecht.

Palloff, R., \& Pratt, K. (2007). Building online learning communities: Effective strategies for the virtual classroom. San Francisco, CA: Jossey-Bass.

Reid, A., \& Loxton, J. (2004). Internationalisation as a way of thinking about curriculum development and quality, in Proceedings from the Australian University Quality Forum 2004, AUQA Occasional Publication.

Siemens, G. (2004). A learning theory for the digital age. Retrieved March 26, 2007 from http://www.elearnspace.org IArticles/connectivism.htm

Wilson, B.G. (1997). Reflections on constructivism and instructional design. In C. R. Dills \& A. J. Romiszowski (eds.), Instructional development paradigms (pp. 63-80). Englewood Cliffs, NJ: Educational Technology Publications.

Sue, D.W., \& Sue, D. (2010). Counseling the culturally diverse: Theory and practice (6th ed.). New York, NY: Wiley.

Zimmerman, B.J. (1998). Academic studying and the development of personal skill: A self-regulatory perspective. Educational Psychologist, 33(2), 73-86.

Zimmerman, B.J., \& Schunk, D.H. (2001). Self-regulated learning and academic achievement: Theoretical perspectives (2nd ed.). Mahwah, NJ.: Lawrence Erlbaum Associates. 